\title{
General declines in Mediterranean butterflies over the last two decades are modulated by species traits
}

Article

Accepted Version

Creative Commons: Attribution-Noncommercial-No Derivative Works 4.0

Melero, Y., Stefanescu, C. and Pino, J. (2016) General declines in Mediterranean butterflies over the last two decades are modulated by species traits. Biological Conservation, 201. pp. 336-342. ISSN 0006-3207 doi:

https://doi.org/10.1016/j.biocon.2016.07.029 Available at https://centaur.reading.ac.uk/83101/

It is advisable to refer to the publisher's version if you intend to cite from the work. See Guidance on citing.

To link to this article DOI: http://dx.doi.org/10.1016/j.biocon.2016.07.029

Publisher: Elsevier

All outputs in CentAUR are protected by Intellectual Property Rights law, including copyright law. Copyright and IPR is retained by the creators or other copyright holders. Terms and conditions for use of this material are defined in the End User Agreement.

www.reading.ac.uk/centaur 
Central Archive at the University of Reading

Reading's research outputs online 
1 General declines in Mediterranean butterflies over the last two decades are modulated by species traits

4 Yolanda Melero ${ }^{\mathrm{a}^{*}}$, Constantí Stefanescu ${ }^{\mathrm{a}, \mathrm{b}}$, Joan Pino $^{\mathrm{a}}$

$5 \quad{ }^{a}$ Centre de Recerca Ecològica i Aplicacions Forestals (CREAF), Universitat

6 Autònoma de Barcelona, Bellaterra, Barcelona, Spain

$7 \quad$ butterfly Monitoring Scheme, Museu de Ciències Naturals de Granollers, Granollers

8 (Barcelona), Spain

10 *Corresponding author. Tel.: +34 935814677. E-mail addresses:

11 y.melero@creaf.uab.cat (Y. Melero), c.stefanescu@creaf.uab.cat (C. Stefanescu), 12 j.pino@creaf.uab.cat (J. Pino)

\section{Abstract}

Species' responses to environmental changes are highly idiosyncratic and contextdependent. Although intrinsic traits (i.e. those that define species niches) may play a key role, little empirical evidence exists regarding their relationship to demographic responses. We used data for 66 butterfly species representing five ecological and two life-history traits to study the effect these factors have on population growth rates and variations in populations. Using a novel methodological approach, we provide here improved estimates of population change. Our results reveal declines in $70 \%$ and

23 increases in $23 \%$ of the studied species, clear evidence of more serious population

24 declines in Catalan butterflies than those that have previously been reported. Declines

25 were associated with species' degree of habitat specialisation and the number of 
26 generations. For all species, fluctuations were greater within than between years and,

27 on average, the latter was 1.5 times greater. Our results indicated that habitat

28 specialists and multivoltine species are more likely to suffer severe annual

29 fluctuations in population abundance; and that multivoltine species and extreme larval

30 specialists had the most marked fluctuations within seasons. We also found higher

31 resilience to environmental changes in generalist species, which is concordant with

32 biotic homogenisation in disturbed communities. However, amongst the declining

33 species there were also many generalists, which indicates a potential general

34 reduction in this group that goes beyond faunal homogenisation. Given butterflies are

35 biodiversity indicators, these patterns are a possible reflection of an overall

36 impoverishment in biodiversity.

37

38 Keywords

39 Population trends, specialization, voltinism, species traits, butterflies, Bayesian

40 hierarchical modeling

41 


\section{Introduction}

44 Understanding the pressures affecting species population dynamics is a central issue

45 in ecology and management, especially when the aim is to safeguard biodiversity

46 (Sutherland et al. 2013). Pressures provoked by global change have accelerated the

47 decline of many species (Vitousek 1997, Chapin et al. 2000, Vitousek et al. 2008),

48 with some facing or undergoing extinction (Butchart et al. 2010, Pimm et al. 2014). In

49 particular, climate change and habitat transformation (i.e. habitat loss and

50 fragmentation) are among the main pressures exerted by global change that species

51 are having to confront (Thomas et al. 2004a, Visconti et al. 2015).

52 Several studies have suggested that certain intrinsic ecological (i.e. those that define

53 species ecological niches) and life-history traits predispose a species to respond

54 distinctly to specific environmental pressures (Krauss et al. 2010, Murray et al. 2011,

55 González-Suárez and Revilla 2013). For instance, species with better dispersal ability

56 can shift their ranges faster than those with less capacity to disperse. This is an

57 advantage in areas in which climate change is provoking asynchronies between the

58 species niche and the environment (e.g. Croxall et al. 2002, Butchart et al. 2010, Chen

59 et al. 2011). Species whose traits enable them to cope well with current pressures are

60 expected to persist while the others might face declines and, eventually, local

61 extinction. It is therefore not surprising that an increasing number of studies have

62 evaluated the relationship between species traits and their responses to environmental

63 pressures.

64 Previous studies have quantified these responses as changes in species richness and

65 distributions for a wide range of taxa (e.g. Thuiller et al. 2008, Stefanescu et al.

66 2011a, Eskildsen et al. 2015), or have evaluated extinction probabilities or 
vulnerability (e.g. González-Suárez and Revilla 2013; Fernández-Chacón et al. 2014).

However, few empirical studies have actually addressed demographic trends in citizen-science projects has provided a useful way of obtaining the data needed for this kind of analysis (Schmeller et al. 2009, Devictor et al. 2010). In this paper we examine the relationship between ecological and life-history traits, and demographic trends in a set of butterfly species. To do so, we used empirical count data gathered by a volunteer-based project, the Catalan Butterfly Monitoring Scheme, over 20 years in the Mediterranean region of north-eastern Spain. Butterflies are good indicators of biodiversity (Thomas 2005) and respond quickly to climate change and habitat transformation (Stefanescu et al. 2003, Thomas et al. 2004b, Krauss et al. 2010), thereby minimising - in comparison, for example, to plants and birds - the demographic time lag inherent in extinction debts (Krauss et al. 2010, Devictor et al. 2012, but see Sang et al. 2010). Therefore, butterfly demographic patterns in relation to species intrinsic traits can contribute to a better understanding of how a wide range of organisms (e.g. insects and other short-lived organisms) respond under such pressures.

To gather species demographic patterns we estimated (i) their population growth rate, i.e. the direction of the population trend (positive, stable or negative) and its strength, and (ii) the population variation, i.e. the dispersion of temporal changes in population numbers due to intrinsic (density-dependence processes) and external (cyclic or stochastic) factors.

90 We hypothesised that habitat specialisation will decrease population growth rate but

91 increase population variability (hypothesis 1), an idea that is based on previous 
studies suggesting the existence of a relationship between this trait and population trends in butterflies (e.g. Stefanescu et al. 2011a; see Dapporto and Dennis 2013 for a

comprehensive discussion). Nevertheless, other traits besides habitat specialisation could also influence demographic trends as the species respond to global change. For instance, dispersal ability in fragmented landscapes is directly related to colonisation and the persistence of butterfly populations (Fernández-Chacón et al. 2014).

Therefore, we predicted that better dispersal ability will increase growth rate and reduce population variability (hypothesis 2). Furthermore, during a period of climate warming, we would expect thermophilous species to have more positive population trends and less population variability than those adapted to colder climates (as seen in birds; e.g. Stephens et al. 2016) (hypothesis 3). In addition, traits influencing butterflies' responses to increasing temperatures may also be important for explaining population trends (e.g. Diamond et al. 2011). A series of studies have suggested that an increase in the number of generations per reproductive season (i.e. the production of extra generations) occurs under climate warming, although its effect on populations remains unclear (e.g. Altermatt 2010, Van Dyck et al. 2015). Intuitively, a positive effect is expected since a larger proportion of adults will develop and reproduce during the season and so we hypothesised that there will be a higher growth rate in multivoltine than in univoltine species (hypothesis 4). Finally, we also predicted more positive trends and less variation in species overwintering in mature (pupa and adult) than in immature stages (egg and larva; hypothesis 5) given previous findings that suggest that species overwintering in the egg stage or as unfed neonate larva are currently undergoing the most serious declines (Breed et al. 2012).

\section{Material and Methods}




\subsection{Study area and data collection}

120 The study area was the Mediterranean region of Catalonia, Menorca (north-east

121 Spain) and Andorra. This area is a biodiversity hotspot in which butterfly species are

122 threatened by climate warming (e.g. increasing aridity; Stefanescu et al. 2011a) and

123 habitat transformation (e.g. the abandonment of traditional land use and increasing

124 urbanisation; Herrando et al. 2015).

125 Data were obtained from monitoring surveys carried out in 1994-2014 as part of the

126 Catalan Butterfly Monitoring Scheme (CBMS; see: www.cbms.org) and the Andorran

127 Butterfly Monitoring Scheme (BMSAnd; see www.iea.ad/bmsand). Both schemes

128 consist of a network of sites in which visual counts of adult butterflies along transects

129 are undertaken by volunteers every week between March and September (i.e. the

130 whole flight period of most species). Transects are fixed routes of about $2 \mathrm{~km}$ in

131 length and $5 \mathrm{~m}$ in width, which are divided into shorter sections corresponding to

132 homogeneous habitat types (average section length: $186 \mathrm{~m}$, median: $162 \mathrm{~m}$, range:

$13320-871 \mathrm{~m})$. The transects used in our study $(\mathrm{n}=116)$ are located at $0-1650 \mathrm{~m}$ a.s.l.

134 and cover a comprehensive range of environmental conditions (Fig. A.1). Although

135 the number of surveyed transects varied between years, an important fraction

136 remained stable throughout the whole recording period (for further details, visit

137 www.catalanbms.org). Nevertheless, our modeling approach allowed us to assess

138 species abundance at sites in years in which surveys were not performed via updating

139 with the Markov Chain Monte Carlo (see next section).

141 2.2. Species selection and modeling approach 
143 A total 183 species were sampled, of which we selected 82 species representative of a

144 diverse range of ecological and life-history traits (Table A.1) and regularly recorded

145 across all years and sites.

147 To test our hypotheses, we applied an open-population binomial mixture Bayesian

148 hierarchical model (Kéry et al. 2009). This model estimates abundance over time

149 using count data from open populations corrected by the imperfect detection inherent

150 to observational error (see full model description in Appendix B and R code in

151 Appendix C). In previous studies (e.g. Stefanescu et al. 2011b; Herrando et al. 2015),

152 population trends were calculated via the widely used TRIM software (Pannekoek and

153 Strien 2005). Nevertheless, this methodological approach does not take into account

154 the detection probability that observational counts are subject to or its variation over

155 time. This could mask real abundances and temporal trends in populations and their

156 drivers (Kéry 2004, Kéry and Plattner 2007, Kéry et al. 2009).

157 For each species, abundance was set as time and section specific, and its estimation

158 was extended to include the relationship with the population growth rate $\left(r_{s p}\right)$ and the

159 seven major habitat types in the area (meadows, forests, arable crops, woody crops,

160 gardens, ruderal vegetation, and non-suitable habitat). Habitat types were not

161 significantly correlated and were expressed as a percentage of habitat per section

162 (Table A.2). The detection probability - with which species abundance was corrected

163 - was set as time-specific.

164

165 The time step was set as intervals of two weeks to account for seasonality in both the

166 abundance and the detection probability, and to include a closure period for the 
repeated counts used to analyse detectability. Two-week intervals have been postulated as an acceptable closure period for butterfly species richness (Kéry and Plattner 2007). Although slight changes in butterfly abundance may occur at this resolution level, we consider that they are small enough to ensure that our model

171 remains valid.

\subsection{Temporal population variability of species abundance}

175 Population variability was assessed using the coefficient of variation (i.e. the 176 dispersion around the mean), a relative measure of variation that is independent of the 177 population size and so can be used to compare species. We used two temporal 178 windows: seasonal (i.e. within years; $\mathrm{CV}_{\mathrm{W}}$ ) to include the seasonality (excluding the 179 seasonality related to non-surveyed months: October-February), and inter-annual 180 variation (i.e. between years; $\mathrm{CV}_{\mathrm{B}}$ ). Seasonal variation was defined as the ratio of the 181 standard deviation to the mean of the time series of abundance within each year, 182 which gave a total of 20 values per species (one for each of the 20 years recorded). To 183 obtain the inter-annual variation without including the seasonal variation in the 184 calculation, we calculated the standard deviation and mean abundance per year and 185 defined $\mathrm{CV}_{\mathrm{B}}$ as their ratio, which generated a single value for each species.

\subsection{Species ecological and life-history traits}

189 For each species, we used a total of seven intrinsic traits divided into five ecological 190 (i-v) and two life-history (vi-vii) traits: (i) adult habitat specialisation measured using 191 the Species Specialisation Index (SSI), quantified as the coefficient of the variations 
in the average density in the available habitat, as defined by Julliard et al. (2006); (ii)

193 larval trophic specialisation, ranging from 1 (extreme specialists) to 3 (extreme generalists), following Stefanescu et al. (2011a) and Fernández-Chacón et al. (2014);

195 (iii) the degree of preference for forests versus open areas, as evaluated by Herrando 196 et al. (2015); (iv) average forewing length (measured in mm), which has been shown 197 to act as a satisfactory proxy for dispersal ability in butterflies (Kuussaari et al. 2014; 198 but see Sekar 2012); for this measurement, data were extracted from García-Barros et 199 al. (2013) with sexes pooled given their close correlation (Fig. A.2); (v) the Species 200 Temperature Index (STI), as defined in Schweiger et al. (2014); (vi) voltinism, 201 categorised as uni-, bi- or multivoltine ( $\geq 3$ generations/year), according to Stefanescu 202 et al. (2011a) and Fernández-Chacón et al. (2014); and (vii) overwintering stage, 203 either immature (i.e. egg or larva) or mature (i.e. pupa or adult), with a third category 204 for migratory species (i.e. not overwintering in the region), as per García-Barros et al. 205 (2013).

\subsection{Statistical analyses}

209 The effects of the seven species traits on the growth rate estimates were tested using

210 linear regressions (i.e. the growth rate fitted to a Gaussian distribution).

211 Both seasonal and inter-annual population variability were analysed in terms of the 212 described traits using a Generalised Linear Mixed Model (GLMM) and a Generalised 213 Linear Model (GLM), respectively. These two models were fitted to a Gamma 214 distribution given that the coefficients of variation were positive, continuous, skewed 215 and of increasing variance; species identity was set as a random effect. 
216 For each analysis, a global model was first defined containing all the above

217 mentioned covariates and potential interactions. Model selection was carried out by

218 discarding terms sequentially. In the case of the linear regression analysis model,

219 selection was based on the adjusted r-squared to take into account the number of

220 observations and of model parameters. Model selection for the generalised models

221 was based on AICc selecting those models differing from $\Delta$ AICc $<2$. Model

222 averaging and estimates weighting for the most likely models were obtained via $\mathrm{R}$

223 package MuMIn (Bartoń 2014). Analyses were performed in R using package lme4

224 (Bates et al. 2014).

225

226 Temporal changes in the detection probability were tested in relation to species

227 voltinism. We used a Generalised Additive Mixed Model (GAMM), with two-week

228 intervals throughout the year (1-15) set as the non-lineal term and species as a

229 random effect, to account for the inherent specific variability. The detection

230 probability was fitted to a Gamma distribution with an inverse link. Analyses were

231 performed in R using package gamm4 (Wood 2014).

232

233 3. Results

234

235 Sixteen of the 82 regularly recorded species failed to converge in our modeling

236 approach (Table A.3). The remaining 66 species were all present in more than 10

237 transects, which conferred inferential strength on the analysis (e.g. Oliver et al. 2010).

238 Annual population growth rates ranged between -0.11 and $0.04\left(\mathrm{r}_{\text {average }}=-0.02\right) ; 15$

239 species $(22.7 \%)$ had a significantly positive rate, five $(7.6 \%)$ were stable and 46

$240(69.7 \%)$ had a negative rate. Significance was based on the exclusion of zero values in 
241 the Bayesian Credible Interval values at 95\% (Appendix D). When testing for

242 significance using a conventional Poisson regression, only one species (Euphydryas

243 aurinia) was considered as stable $(\mathrm{r}=0.00035, \mathrm{z}=0.92, \mathrm{p}=0.36$; Appendix D).

\subsection{Population growth rate and species traits}

247 The best models for the estimated population growth rates included habitat

248 specialisation, the degree of preference for forests versus open areas, wing length and 249 voltinism (Table A.4).

250 Population growth rates decreased with the increase in habitat specialisation, thereby

251 indicating lower population growth rate in habitat specialists $(\mathrm{p}=0.021$, Table 1a,

252 Fig. 1b). Nevertheless, several generalist species did also show declines (e.g. 71\% of

253 those species with SSI $<1.5$, for range, median and average values of $0.62-2.18,1.23$

254 and 1.24, respectively). Multivoltine species had a steeper negative rate than both uni255 and bivoltine species (Table 1a, Fig. 1b). Results also suggested steeper negative rates 256 in forest species; however, this effect was not significant. The effect of wing length 257 similarly not significant - was nearly negligible despite being included in the best 258 models (Table 1a).

\subsection{Temporal variation of abundance and species traits}

262 Seasonal variation was greater than inter-annual variation in species abundance

263 (range $=0.004-1.54$ and $0.05-0.72$, respectively), although the mean value of the

264 inter-annual variation was 1.5 times higher (average $=0.14$ and 0.22 for seasonal and 265 inter-annual variation, respectively; Fig. A.3). 
266 Although $38 \%$ of the seasonal variation was species-specific, voltinism was the main

267 factor involved, as variation increased from uni- to multivoltine species (all $\mathrm{p}$

$268<0.0001$; Table 1b, Fig. 2a). Seasonal variation was lesser in larval trophic generalists

269 (i.e. larval specialisation $3, \mathrm{p}=0.006$ ) and species overwintering in an immature stage

$270(p=0.003$; Table 1b, Fig. A4). Habitat specialisation and the degree of preference for

271 forests versus open areas were also included in the best models but without any

272 significant relationship (Tables $1 \mathrm{~b}$ and A.5a).

273 Voltinism and habitat specialisation were the main factors defining inter-annual

274 variation, both leading to increased values $(\mathrm{p}<0.04$; Table 1c, Fig. 2b). The degree of

275 preference for forests versus open areas was included in the best models (Table A.5b),

276 increasing the inter-annual variation non-significantly (Table 1c). No other traits were 277 included in the best models (Table A.5).

278

\subsection{Temporal changes in detection probability}

280

281 The detection probability increased linearly over the years (Estimate $=-0.006)$ for all 282 uni-, bi- and multivoltine species. Although there were no differences between these 283 species ( pinteractions $>0.11$ ), the detection probability was constantly lower for 284 univoltine species $(\mathrm{Q} 1=0.01$; Estimate $=1.12, \mathrm{p}<0.001 ;$ Fig. 1a) .

\section{Discussion}

288 This study reveals negative trends in $70 \%$ of the studied species, indicating a severe 289 decline among Mediterranean butterflies. Population trends are partly predicted by the 
ecological and life-history traits of the species. In particular habitat specialisation and

291 voltinism have the highest influence, whilst other traits have a marginal or null effect.

\subsection{Population trends and species traits}

Population growth rates decreased with increasing habitat specialisation. This finding agrees with the steeper declines detected in populations of butterfly specialists (compared to habitat generalists) in the same region (Stefanescu et al. 2011b; Carnicer et al. 2013) and in other European countries (van Swaay et al. 2006, Eskildsen et al. 2015, Curtis et al. 2015). Habitat generalists have a wider range of available resources that can fulfil their needs, which give them an advantage in environments that are being transformed. Under a context of global change, this may in turn lead to a biotic homogenisation of natural communities, i.e. the substitution of many specialists by a few generalist species, a process that is one of the main drivers of declines in biodiversity worldwide (McKinney and Lockwood, 1999). This effect has been noted to occur in the butterfly fauna in several European countries (e.g. Ekroos et al. 2010, Ockinger et al. 2010).

307 Despite the negative relationship between habitat specialisation and population rates, 308 many generalist species were also found to be in decline. This situation is comparable 309 to some extent to other areas affected by severe anthropic pressure (Leon-Cortes et al. 310 1999, 2000, Van Dyck et al. 2009). Further investigation is needed to evaluate 311 whether or not these general negative trends can be explained by the interaction of 312 environmental pressures such as climate change and habitat transformation, and by 313 ecological traits. For example, Stefanescu et al. (2011a) suggested that habitat 314 generalist species are most affected by the increase of aridity and landscape 
315 intensification in lowlands, while specialists are more affected by land abandonment

316 and climate warming in mountain areas.

317 In contrast to our intuitive expectation, uni- and bivoltine species registered similar

318 trends, while multivoltine species had significantly steeper declines. For example, in

319 Germany multivoltine species dominate butterfly communities when land use

320 intensification is severe (Börschig et al. 2013). However, multivoltine species may be

321 the most negatively affected by climate change in the Mediterranean when their last

322 summer generations have to confront the most rigorous conditions and extreme

323 drought events. To a degree, this situation is comparable with the recent decline of the

324 generalist multivoltine butterfly Lasiommata megera in central Europe, where the

325 addition of an extra generation represents a developmental trap resulting in high larval

326 mortality (Van Dyck et al. 2015). Likewise, multivoltinism could expose a species to

327 detrimental events several times in the same season and thus lead to a severe decline,

328 a scenario that could become more relevant given longer and more frequent extreme

329 climatic events, as predicted by Giorgi and Lionello (2008) for the Mediterranean

330 region.

331 Strikingly, the degree of preference for forests versus open areas was not significant

332 for either population growth rate or variation, which may indicate that we failed to

333 capture this effect properly for the set of studied species. In a recent study this

334 preference was found to be advantageous both for butterflies and birds, as woodland

335 species had more positive population trends (Herrando et al. 2015). Nevertheless, in

336 this study trends were evaluated in a subset of transects covered by natural vegetation

337 affected by land abandonment $(n=74)$ rather than in all available transects, as was

338 the case in our study $(\mathrm{n}=116)$. The addition of other types of habitat transformations 
such as increasing urbanisation probably diluted the positive trend of forests in natural areas at a regional scale.

341 Wing length, which we considered as a proxy for dispersal, had nearly no effect in our

342 models. However, some authors have questioned its relationship with dispersal ability

343 (see Sekar 2012). In addition, the fact that the Species Temperature Index did not

344 predict population trends may initially be surprising given the prediction of general

345 declines in cold-adapted species and the opposite trends in warm-adapted species in

346 the current context of climate warming (e.g. Devictor et al. 2012). However, our

347 results confirm some previous analyses at site level that show that population trends

348 are in fact independent of the thermal niche of the species (Stefanescu et al. 2011b).

349 Indeed, our findings suggest that interactions with other climatic and non-climatic

350 factors may be more important for explaining population trends (Oliver et al. 2015,

351 Settele and Wiemers 2015).

\subsection{Temporal population variation and species traits}

Although seasonal variation was greater than inter-annual variation, average values showed the opposite pattern. Both measures were positively affected by voltinism, that is, population variation at differing time scales was higher in multivoltine species,

358 which suggests that there was a higher risk of strong fluctuations.

359 To a lesser degree, seasonal variation was affected by extreme larval trophic

360 generalism and the overwintering stage. The lower variability in larval trophic

361 generalism supports the hypothesis of specialisation traits relating to higher sensitivity

362 to environmental changes. Likewise, fewer seasonal variations were found in species

363 overwintering in immature stages (egg or pupa), which could indicate a major 
364 buffering capacity in immature stages against extreme climatic events, a result that

365 contrasts with the findings of Breed et al. (2012). Indeed, species overwintering in

366 mature stages will emerge earlier in the spring, thereby exposing themselves to

367 extreme climatic events at the beginning of the season that could provoke fluctuations

368 in populations.

369 In addition to voltinism, inter-annual variation was also affected by habitat

370 specialisation, with habitat specialists showing consistently greater variation than

371 habitat generalists. This interesting finding - that we interpret to be a reflection of the

372 greater sensitivity of habitat specialists to environmental perturbations - highlights

373 how difficult it is for these species to adapt to the ongoing environmental

374 transformations (in both climate and landscape) in the region. This agrees with the 375 differences in the relative impact of environmental perturbations on specialist and 376 generalist species richness (Stefanescu et al. 2011a).

\subsection{Modeling approach: open-population Binomial Hierarchical Bayesian}

The percentage of declining species obtained with our approach was almost two times higher than previously obtained with TRIM for the region (Fig. A.5; Stefanescu et al. 2011b; Carnicer et al. 2013).

383 Different estimates of abundance between models are to be expected whenever trends

384 in detection probability occurred, as our model accounted for the error in the 385 observational process while TRIM does not. In the later model type, abundances are 386 likely to be underestimated when the detection probability is low. The increasing 387 probability of detection over time in our data (Fig. 1A) means that population trends 388 will be underestimated when the population trend is negative because there will be 
fewer differences between the (under)estimates of abundances during the first years of surveys and the estimates during the latter years. However, they will be overestimated

391 when the population trend is positive since there will be greater differences between 392 the (under)estimates of abundances during the first years of surveys and the estimates

393 during the latter years. In our case, the detection probability increased over time,

394 probably due to the lower amount of experience of the volunteers at the start of the 395 project. Thus, our estimations gained in accuracy by adding the detection probability.

396 The benefit of accounting for the detection probability has been demonstrated by Dail 397 and Madsen (2011) and Pellet et al. (2012).

398 The differences in the results obtained using our approach and TRIM could also be 399 explained by the different parameterisation of the time scale of the models (every two 400 weeks versus annual) and the model structure (lineal versus non-lineal). Therefore, 401 although we recommend the use of models that take into account the detection 402 probability to reduce uncertainty caused by observational error, we are unable to 403 endorse any particular approach until further comparisons between these two 404 methodologies using equal parameterisations have been conducted.

\section{Conclusions}

408 Our results indicate a very serious general decline of the butterfly fauna in the western

409 Mediterranean, affecting $70 \%$ of the studied species. Although this decline also

410 covers many generalist species, overall the highest vulnerability in terms of

411 population trends was found for specialist and multivoltine species. Taken together

412 with previous work, our analysis suggests that global change - including land

413 abandonment and intensification and climate change - is behind the observed 
negative trends (Stefanescu et al. 2003, 2011a,b; Herrando et al. 2015). Moreover,

415 changes in land cover and more extreme climatic events are expected to exacerbate

416 these serious declines in the future. Furthermore, given that butterflies are also

417 regarded as good indicators for other terrestrial insects (Thomas 2005; but see

418 Musters et al. 2013), the observed patterns may also be indicative of global biological

419 impoverishment. Under this scenario, local habitat management (i.e. conservation

420 aimed at increasing habitat availability and connectivity) focused on the requirements

421 of declining species might help mitigate these negative trends (Curtis et al. 2015) or

422 even potentially revert population declines (e.g. Dapporto and Dennis 2013).

423 Finally, this study also highlights the potential of models that take into account

424 detection probability and provides empirical evidence for their robustness and

425 usefulness with volunteer-based projects and monitoring programs. Therefore, we

426 recommend their use if temporal or spatial variation in the observational error is

427 suspected to occur.

\section{Acknowledgements}

431 We would like to thank all the volunteers who helped gather the data in the butterfly

432 monitoring schemes, as well as Chris Sutherland for checking the R code for the

433 Bayesian model and Arco van Strien for providing useful comments on the

434 manuscript. Ferran Páramo provided technical assistance. The CBMS is funded by the

435 Departament de Territori i Sostenibilitat de la Generalitat de Catalunya and the

436 BMSAnd by the Andorran Research Institute. Funding was also provided by

437 Barcelona Provincial Council as part of the SITxell project. YM was supported by a

438 Beatriu de Pinos-B grant (2013 BP-B 00168) from AGAUR for postdoctoral 
researchers. We are also grateful to the three anonymous reviewers for their help in improving the manuscript. A professional scientific proof-reader (Mike Lockwood) revised the manuscript.

\section{References}

Altermatt, F. 2010. Climatic warming increases voltinism in European butterflies and moths. Proceedings of the Royal Society B 277:1281-1287.

Bartoń, K. 2014. MuMIn: Multi-model inference. R package version 1.10.5.

Bates, D., M. Maechler, B. Bolker, and S. Walker. 2014. lme4: Linear mixed-effects models using Eigen and S4 version 1:1-7.

Börschig, C., A.-M. Klein, H. von Wehrden, and J. Krauss. 2013. Traits of butterfly communities change from specialist to generalist characteristics with increasing land-use intensity. Basic and Applied Ecology 14:547-554.

Breed, G. A., S. Stichter, and E. E. Crone. 2012. Climate-driven changes in northeastern US butterfly communities. Nature Climate Change 3:142-145.

Butchart, S. H. M., M. Walpole, B. Collen, A. van Strien, J. P. W. Scharlemann, R. E. A. Almond, J. E. M. Baillie, B. Bomhard, C. Brown, J. Bruno, K. E. Carpenter, G. M. Carr, J. Chanson, A. M. Chenery, J. Csirke, N. C. Davidson, F. Dentener, M. Foster, A. Galli, J. N. Galloway, P. Genovesi, R. D. Gregory, M. Hockings, V. Kapos, J.-F. Lamarque, F. Leverington, J. Loh, M. A. McGeoch, L. McRae, A. Minasyan, M. H. Morcillo, T. E. E. Oldfield, D. Pauly, S. Quader, C. Revenga, J. R. Sauer, B. Skolnik, D. Spear, D. Stanwell-Smith, S. N. Stuart, A. Symes, M. Tierney, T. D. Tyrrell, J.-C. Vié, and R. Watson. 2010. Global Biodiversity: Indicators of Recent Declines. Science 328:1164-1168.

Carnicer, J., C. Stefanescu, R. Vila, V. Dinca, X. Font, and Josep Peñuelas. 2013. A unified framework for diversity gradients: the adaptive trait continuum. Global Ecology and Biogeography 22:6-18.

Chapin, F. S. I., E. S. Zavaleta, V. T. Eviner, R. L. Naylor, P. M. Vitousek, H. L. Reynolds, D. U. Hooper, S. Lavorel, O. E. Sala, S. E. Hobbie, M. C. Mack, and S. Diaz. 2000. Consequences of changing biodiversity. Nature 405:234-242.

Chen, I.-C., J. K. Hill, R. Ohlemüller, D. B. Roy, and C. D. Thomas. 2011. Rapid range shifts of species associated with high levels of climate warming. Science 333:1024-1026.

Croxall, J. P., P. N. Trathan, and E. J. Murphy. 2002. Environmental change and Antarctic seabird populations. Science 297:1510-1504.

Curtis, R. J., T. M. Brereton, R. L. H. Dennis, C. Carbone, and N. J. B. Isaac. 2015. Butterfly abundance is determined by food availability and is mediated by species traits. Journal of Applied Ecology 52:1676-1684. 
Dail, D., and L. Madsen. 2011. Models for estimating abundance from repeated counts of an open metapopulation. Biometrics 67:577-87.

Dapporto, L., and R. L. H. Dennis. 2013. The generalist-specialist continuum: Testing predictions for distribution and trends in British butterflies. Biological Conservation 157:229-236.

Devictor, V., C. van Swaay, T. Brereton, L. Brotons, D. Chamberlain, J. Heliölä, S. Herrando, R. Julliard, M. Kuussaari, Å. Lindström, J. Reif, D. B. Roy, O. Schweiger, J. Settele, C. Stefanescu, A. Van Strien, C. Van Turnhout, Z. Vermouzek, M. WallisDeVries, I. Wynhoff, and F. Jiguet. 2012. Differences in the climatic debts of birds and butterflies at a continental scale. Nature Climate Change 2:121-124.

Devictor, V., R. J. Whittaker, and C. Beltrame. 2010. Beyond scarcity: citizen science programmes as useful tools for conservation biogeography. Diversity and Distributions 16:354-362.

Diamond, S. E., A. M. Frame, R. A. Martin, and L. B. Buckley. 2011. Species' traits predict phenological responses to climate change in butterflies. Ecology 92:1005-1012.

Ekroos, J., J. Heliölä, and M. Kuussaari. 2010. Homogenization of lepidopteran communities in intensively cultivated agricultural landscapes. Journal of Applied Ecology 47:459-467.

Eskildsen, A., L. G. Carvalheiro, W. D. Kissling, J. C. Biesmeijer, O. Schweiger, and T. T. Høye. 2015. Ecological specialization matters: long-term trends in butterfly species richness and assemblage composition depend on multiple functional traits. Diversity and Distributions 21:792-802.

Fernández-Chacón, A., C. Stefanescu, M. Genovart, J. D. Nichols, J. E. Hines, F. Páramo, M. Turco, and D. Oro. 2014. Determinants of extinction-colonization dynamics in Mediterranean butterflies: the role of landscape, climate and local habitat features. Journal of Animal Ecology 83:276-285.

García-Barros, E., M. L. Munguira, C. Stefanescu, and A. Vives Moreno. 2013. Lepidoptera Papilionoidea. Fauna Ibérica. Museo Nacional de Ciencias Naturales. CSIC, Madrid.

Giorgi, F., and P. Lionello. 2008. Climate change projections for the Mediterranean region. Global and Planetary Change 63:90-104.

González-Suárez, M., and E. Revilla. 2013. Variability in life-history and ecological traits is a buffer against extinction in mammals. Ecology Letters 16:242-251.

Herrando, S., L. Brotons, M. Anton, F. Páramo, D. Villero, N. Titeux, J. Quesada, and C. Stefanescu. 2015. Assessing impacts of land abandonment on Mediterranean biodiversity using indicators based on bird and butterfly monitoring data. Environmental Conservation:1-10.

Julliard, R., J. Clavel, V. Devictor, F. Jiguet, and D. Couvet. 2006. Spatial segregation of specialists and generalists in bird communities. Ecology Letters 9:1237-1244.

Kéry, M. 2004. Extinction Rate Estimates for Plant Populations in Revisitation Studies: Importance of Detectability. Conservation Biology 18:570-574. 
Kéry, M., R. M. Dorazio, L. Soldaat, A. van Strien, A. Zuiderwijk, and J. A. Royle. 2009. Trend estimation in populations with imperfect detection. Journal of Applied Ecology 46:1163-1172.

Kéry, M., and M. Plattner. 2007. Species richness estimation and determinants of species detectability in butterfly monitoring programmes. Ecological Entomology 32:53-61.

Krauss, J., R. Bommarco, M. Guardiola, R. K. Heikkinen, A. Helm, M. Kuussaari, R. Lindborg, E. Ockinger, M. Pärtel, J. Pino, J. Pöyry, K. M. Raatikainen, A. Sang, C. Stefanescu, T. Teder, M. Zobel, and I. Steffan-Dewenter. 2010. Habitat fragmentation causes immediate and time-delayed biodiversity loss at different trophic levels. Ecology Letters 13:597-605.

Kuussaari, M., M. Saarinen, E.-L. Korpela, J. Pöyry, and T. Hyvönen. 2014. Higher mobility of butterflies than moths connected to habitat suitability and body size in a release experiment. Ecology and Evolution 4:3800-3811.

Leon-Cortes, J. L., M. J. R. Cowley, and C. D. Thomas. 1999. Detecting decline in a formerly widespread species: how common is the common blue butterfly Polyommatus icarus? Ecography 22:643-650.

Leon-Cortes, J. L., M. J. R. Cowley, and C. D. Thomas. 2000. The distribution and decline of a widespread butterfly Lycaena phlaeas in a pastoral landscape. Ecological Entomology 25:285-294.

McKinney, M. L., and J. L. Lockwood. 1999. Biotic homogenization: a few winners replacing many losers in the next mass extinction. Trends in Ecology \& Evolution 14:450-453.

Murray, K. A., D. Rosauer, H. McCallum, and L. F. Skerratt. 2011. Integrating species traits with extrinsic threats: closing the gap between predicting and preventing species declines. Proceedings of the Royal Society B 278:1515-23.

Musters, C. J. M., V. Kalkman, and A. van Strien. 2013. Predicting rarity and decline in animals, plants, and mushrooms based on species attributes and indicator groups. Ecology and Evolution 3:3401-3414.

Ockinger, E., O. Schweiger, T. O. Crist, D. M. Debinski, J. Krauss, M. Kuussaari, J. D. Petersen, J. Pöyry, J. Settele, K. S. Summerville, and R. Bommarco. 2010. Life-history traits predict species responses to habitat area and isolation: a crosscontinental synthesis. Ecology Letters 13:969-979.

Oliver, T. H., H. H. Marshall, M. D. Morecroft, T. Brereton, C. Prudhomme, and C. Huntingford. 2015. Interacting effects of climate change and habitat fragmentation on drought-sensitive butterflies. Nature Climate Change 5:941945.

Oliver, T., D. B. Roy, J. K. Hill, T. Brereton, and C. D. Thomas. 2010. Heterogeneous landscapes promote population stability. Ecology Letters 13:473-484.

Pannekoek, J., and A. Strien. 2005. TRIM 3. Trends and indices for monitoring data. CBS, Statistics Netherlands, Voorburg, Netherlands.

Pellet, J., J. T. Bried, D. Parietti, A. Gander, P. O. Heer, D. Cherix, and R. Arlettaz. 2012. Monitoring butterfly abundance: beyond Pollard walks. PloS ONE 
Pimm, S. L., C. N. Jenkins, R. Abell, T. M. Brooks, J. L. Gittleman, L. N. Joppa, P. H. Raven, C. M. Roberts, and J. O. Sexton. 2014. The biodiversity of species and their rates of extinction, distribution, and protection. Science 344:1246752.

Sang, A., T. Teder, A. Helm, and M. Pärtel. 2010. Indirect evidence for an extinction debt of grassland butterflies half century after habitat loss. Biological Conservation 143:1405-1413.

Schmeller, D. S., P.-Y. Henry, R. Julliard, B. Gruber, J. Clobert, F. Dziock, S. Lengyel, P. Nowicki, E. DériI, E. Budrys, T. Kull, K. Tali, B. Bauch, J. Settele, C. Van Swaay, A. Kobler, V. Babij, E. Papastergiadou, and K. Henle. 2009. Advantages of Volunteer-Based Biodiversity Monitoring in Europe. Conservation Biology 23:307-316.

Schweiger, O., A. Harpke, M. Wiemers, and J. Settele. 2014. CLIMBER: Climatic niche characteristics of the butterflies in Europe. ZooKeys 367:65-84.

Sekar, S. 2012. A meta-analysis of the traits affecting dispersal ability in butterflies: can wingspan be used as a proxy? Journal of Animal Ecology 81:174-84.

Settele, J., and M. Wiemers. 2015. Biodiversity: Interacting global change drivers. Nature Climate Change 5:913-914.

Stefanescu, C., J. Carnicer, and J. Peñuelas. 2011a. Determinants of species richness in generalist and specialist Mediterranean butterflies: the negative synergistic forces of climate and habitat change. Ecography 34:353-363.

Stefanescu, C., J. Penuelas, and I. Filella. 2003. Effects of climatic change on the phenology of butterflies in the northwest Mediterranean Basin. Global Change Biology 9:1494-1506.

Stefanescu, C., I. Torre, J. Jubany, and F. Páramo. 2011b. Recent trends in butterfly populations from north-east Spain and Andorra in the light of habitat and climate change - Springer. Journal of Insect Conservation 15:83-93.

Stephens, P. A., L. R. Mason, R. E. Green, R. D. Gregory, J. R. Sauer, J. Alison, A. Aunins, L. Brotons, S. H. M. Butchart, T. Campedelli, T. Chodkiewicz, P. Chylarecki, O. Crowe, J. Elts, V. Escandell, R. P. B. Foppen, H. Heldbjerg, S. Herrando, M. Husby, F. Jiguet, A. Lehikoinen, A. Lindstrom, D. G. Noble, J.-Y. Paquet, J. Reif, T. Sattler, T. Szep, N. Teufelbauer, S. Trautmann, A. J. van Strien, C. A. M. van Turnhout, P. Vorisek, and S. G. Willis. 2016. Consistent response of bird populations to climate change on two continents. Science 352:84-87.

Sutherland, W. J., R. P. Freckleton, H. C. J. Godfray, S. R. Beissinger, T. Benton, D. D. Cameron, Y. Carmel, D. A. Coomes, T. Coulson, M. C. Emmerson, R. S. Hails, G. C. Hays, D. J. Hodgson, M. J. Hutchings, D. Johnson, J. P. G. Jones, M. J. Keeling, H. Kokko, W. E. Kunin, X. Lambin, O. T. Lewis, Y. Malhi, N. Mieszkowska, E. J. Milner-Gulland, K. Norris, A. B. Phillimore, D. W. Purves, J. M. Reid, D. C. Reuman, K. Thompson, J. M. J. Travis, L. A. Turnbull, D. A. Wardle, and T. Wiegand. 2013. Identification of 100 fundamental ecological questions. Journal of Ecology 101:58-67.

Thomas, C. D., A. Cameron, R. E. Green, M. Bakkenes, L. J. Beaumont, Y. C. 
Collingham, B. F. N. Erasmus, M. F. de Siqueira, A. Grainger, L. Hannah, L. Hughes, B. Huntley, A. S. van Jaarsveld, G. F. Midgley, L. Miles, M. A. OrtegaHuerta, A. Townsend Peterson, O. L. Phillips, and S. E. Williams. 2004a. Extinction risk from climate change. Nature 427:145-148.

Thomas, J. A. 2005. Monitoring change in the abundance and distribution of insects using butterflies and other indicator groups. Philosophical transactions of the Royal Society of London. Series B, Biological sciences 360:339-57.

Thomas, J. A., M. G. Telfer, D. B. Roy, C. D. Preston, J. J. D. Greenwood, J. Asher, R. Fox, R. T. Clarke, and J. H. Lawton. 2004b. Comparative losses of British butterflies, birds, and plants and the global extinction crisis. Science 303:187981.

Thuiller, W., C. Albert, M. B. Araújo, P. M. Berry, M. Cabeza, A. Guisan, T. Hickler, G. F. Midgley, J. Paterson, F. M. Schurr, M. T. Sykes, and N. E. Zimmermann. 2008. Predicting global change impacts on plant species' distributions: Future challenges. Perspectives in Plant Ecology, Evolution and Systematics 9:137-152.

Van Dyck, H., D. Bonte, R. Puls, K. Gotthard, and D. Maes. 2015. The lost generation hypothesis: could climate change drive ectotherms into a developmental trap? Oikos 124:54-61.

Van Dyck, H., A. J. Van Strien, D. Maes, and C. A. M. Van Swaay. 2009. Declines in Common, Widespread Butterflies in a Landscape under Intense Human Use. Conservation Biology 23:957-965.

Van Swaay, C., M. Warren, and G. Loïs. 2006. Biotope Use and Trends of European Butterflies. Journal of Insect Conservation 10:189-209.

Visconti, P., M. Bakkenes, D. Baisero, T. Brooks, S. H. M. Butchart, L. Joppa, R. Alkemade, M. Di Marco, L. Santini, M. Hoffmann, L. Maiorano, R. L. Pressey, A. Arponen, L. Boitani, A. E. Reside, D. P. van Vuuren, and C. Rondinini. 2015. Projecting Global Biodiversity Indicators under Future Development Scenarios. Conservation Letters 9:5-13.

Vitousek, P. M. 1997. Human Domination of Earth's Ecosystems. Science 277:494499.

Vitousek, P. M., H. A. Mooney, J. Lubchenco, and J. M. Melillo. 2008. Human Domination of Earth's Ecosystems. Pages 3-13 Urban Ecology: An International Perspective on the Interaction Between Humans and Nature. Springer.

Wood, F. S. 2014. gamm4: Generalized additive mixed models using mgcv and lme4. R package version 0.2-3. 
643 Fig 1. Observed (dots) and model derived predictions (lines) for (a) the detection 644 probability in relation to years; (b) population growth rates $(r)$ in relation to the

645 Species Specialisation Index (SSI) for univoltine (black), bivoltine (yellow) and

646 multivoltine species (blue). In both figures, $\mathrm{n}_{\text {univoltine }}=30, \mathrm{n}_{\text {bivoltine }}=11$ and $\mathrm{n}_{\text {multivoltine }}$

$647=25$. Parameters were estimated using weighted estimates of the best models.

648 Continuous lines relate to the estimated fit that sets all the other covariates as constant 649 at their median value; dashed lines denote the $95 \%$ confidence intervals.

650

651 Fig 2. (a) Violin plots for the seasonal coefficient of variation in the abundance of the 652 butterfly species $\left(\mathrm{CV}_{\mathrm{W}}\right)$ in relation to their voltinism, grey shapes show the density 653 distribution of the y-axis covariate, grey circles stand for the median, black bars for 654 the quartiles Q1 and Q3; (b) observed data (dots) and model-derived predictions 655 (lines) for the inter-annual variation $\left(\mathrm{CV}_{\mathrm{B}}\right)$ in relation to the Species Specialisation 656 Index (SSI) for univoltine (black squares), bivoltine (yellow circles) and multivoltine 657 species (blue triangles). In both figures, $\mathrm{n}_{\text {univoltine }}=30, \mathrm{n}_{\text {bivoltine }}=11$ and $\mathrm{n}_{\text {multivoltine }}=$ 658 25. Parameters were estimated using weighted estimates of the best models.

659 Continuous lines relate to the transformed estimated fit setting all the other covariates 660 as constant at their median value; dashed lines denote the $95 \%$ confidence intervals. 
Table 1. Weighted parameter estimates of the effect sizes and the associated standard

663 errors of the species traits retained in the best models for (a) population growth rates,

664 (b) the seasonal $\left(\mathrm{CV}_{\mathrm{W}}\right)$ and $(\mathrm{c})$ inter-annual $\left(\mathrm{CV}_{\mathrm{B}}\right)$ coefficients of variation in the

665 abundance of the butterfly species. Models for CV were fitted to a Gamma

666 distribution with an inverse link (i.e. estimates are produced with an inverted sign);

667 estimates are expressed within this distribution. Significant $\mathrm{p}$ values are marked in 668 italics.

669

\begin{tabular}{|c|c|c|c|c|}
\hline Parameter & Estimate & Std. Error & t or $\mathrm{z}$ value & $\begin{array}{l}\mathrm{p} \text { value } \\
\left(\mathrm{H}_{0}=\text { Estimate }=0\right)\end{array}$ \\
\hline \multicolumn{5}{|l|}{ (a) } \\
\hline Intercept: vol-univoltine & $8 e-4$ & $9 \mathrm{e}-4$ & 0.837 & 0.403 \\
\hline vol-bivoltine & $1 \mathrm{e}-4$ & $6 e-4$ & 0.170 & 0.865 \\
\hline vol-multivoltine & -0.001 & $4 e-4$ & 2.163 & 0.031 \\
\hline SSI & -0.001 & $6 e-4$ & 2.304 & 0.021 \\
\hline of-e & -0.007 & 0.012 & 0.558 & 0.577 \\
\hline wl & $4 e-4$ & $1 e-5$ & 0.274 & 0.784 \\
\hline \multicolumn{5}{|l|}{ (b) } \\
\hline $\begin{array}{l}\text { (Intercept): 1s-1, ow- } \\
\text { immature, vol-univoltine }\end{array}$ & 6.003 & 0.457 & 13.127 & $<2 e-16$ \\
\hline vol-bivoltine & -1.585 & 0.399 & -3.970 & $7 e-5$ \\
\hline vol-multivoltine & -1.769 & 0.325 & -5.444 & $1 e-7$ \\
\hline SSI & -0.200 & 0.388 & 0.515 & 0.607 \\
\hline ls-2 & 0.554 & 0.325 & 1.702 & 0.088 \\
\hline ls-3 & 1.099 & 0.403 & 2.724 & 0.006 \\
\hline
\end{tabular}




\begin{tabular}{|l|r|r|r|r|}
\hline of-e & 12.025 & 8.475 & 1.419 & 0.156 \\
\hline ow-mature & -0.957 & 0.326 & 2.934 & 0.003 \\
\hline ow-migratory & 0.113 & 0.683 & 0.165 & 0.869 \\
\hline random effect & Variance & Std.Dev. & Residual & Std.Dev. \\
\hline Species & 0.380 & 0.617 & 0.436 & 0.660 \\
\hline (c) & & & & $<2 e-16$ \\
\hline Intercept: vol-univoltine & 8.686 & 1.169 & 7.285 & 0.039 \\
\hline vol-bivoltine & -1.764 & 0.842 & 2.057 & $8 e-4$ \\
\hline vol-multivoltine & -2.423 & 0.715 & 3.325 & 0.002 \\
\hline SSI & -2.231 & 0.722 & 3.031 & 0.348 \\
\hline of-e & -16.843 & 17.755 & 0.939 & \\
\hline
\end{tabular}

670

671 SSI: Species Specialisation Index; ls: larval trophic specialisation; of-e: open-forest

672 estimate; wl: wing length; STI: Species Temperature Index; vol: voltinism; ow:

673 overwintering stage

674

675

676

677

678 